\title{
QUANTIFYING LODGING PERCENTAGE, LODGING DEVELOPMENT AND LODGING SEVERITY USING A UAV-BASED CANOPY HEIGHT MODEL
}

\author{
Norman Wilke ${ }^{1}$, Bastian Siegmann ${ }^{1}$, Felix Frimpong ${ }^{1}$, Onno Muller ${ }^{1}$, Lasse Klingbeil ${ }^{2}$, Uwe Rascher ${ }^{1}$ \\ ${ }^{1}$ Institute of Bio- and Geosciences, Plant Sciences (IBG-2), Forschungszentrum Jülich GmbH, 52428 Jülich, Germany - (n.wilke, \\ b.siegmann, o.muller, f.frimpong, u.rascher)@fz-juelich.de \\ ${ }^{2}$ Department of Geodesy, University of Bonn, 53115 Bonn, Germany - klingbeil@igg.uni-bonn.de
}

KEY WORDS: lodging percentage and severity, canopy height model (CHM), precision agriculture, remote sensing, unmanned aerial vehicles (UAVs), structure from motion (SfM).

\begin{abstract}
:
Unmanned Aerial Vehicles (UAVs) are increasingly used, and open new opportunities, in agriculture and phenotyping because of the flexible data acquisition. In this study the potential of ultra-high spatially resolved UAV image data was investigated to quantify lodging percentage, lodging development and lodging severity of barley using Structure from Motion techniques. The term lodging is defined as the permanent displacement of a plant from the upright position. Traditionally lodging quantification is based on observations that need, and vary with observers in the field. An objective threshold approach was proposed in this study to improve the accuracy in lodging determination. Across breeding trials, manual reference measurements and UAV based lodging percentage showed a very high correlation $\left(\mathrm{R}^{2}=0.96\right)$. In addition, the multi-temporal lodging percentage development was used to estimate the recovery rate and to determine the influence of different lodging events. Based on the parameter lodging percentage an approach was developed that allowed the assessment of lodging severity, an information that is important to estimate the yield impairment. Lodging severity can be used for insurance applications, precision farming and breeder research. This trait, together with differentiated recovery are novel traits next to lodging severity that will aid the selection for genetic lines.
\end{abstract}

\section{INTRODUCTION}

The increasing digitalization in agriculture is caused by the rapid development in sensor technology and data processing (Atzberger, 2013; Siegmann and Jarmer, 2015). The use of unmanned aerial vehicles (UAVs) can help to advance and accelerate this process to phenotype plants in short time periods (Burkart et al., 2017; Gómez-Candón et al., 2014; Zhang and Kovacs, 2012).The versatile applications of UAVs in agriculture and other areas are caused by their low costs, simple handling and high flexibility (Eling et al., 2015; Grenzdörffer et al., 2008; Hodgson et al., 2016; Mancini et al., 2013). The possibility to acquire ultra-high resolution spatial UAV data in comparison to satellite and airborne systems, however, is a basic requirement to assess the three-dimensional (3D) canopy structure of crops using feature matching and Structure from Motion (SfM) techniques (Colomina and Molina, 2014; Dandois and Ellis, 2013; Turner et al., 2012). The 3D canopy structure acquired with a red, green and blue (RGB) camera was applied to assess three plant traits (lodging percentage, lodging development, lodging severity).

To deviate the canopy height from the canopy structure a nonvegetated ground model is needed. This ground model determines the top soil surface and is normally acquired via UAV overflight (Bendig et al., 2013; Chu et al., 2017).

The potential of UAV derived canopy height were already evaluated in several studies (Anthony et al., 2014; De Souza et al., 2017; Stanton et al., 2017), in detail for multi-temporal growth curve generation (Chu et al., 2017; Holman et al., 2016) or biomass estimation (Bendig et al., 2015, 2014). Compared to the classical plant height measurements collected with a measuring ruler at a specific position, the UAV approach allows to derive the height of the complete canopy (Aasen et al., 2015; Bendig, 2015). Thus, the UAV based canopy height implied various height information in contrast to the plant height measurement in the field with a ruler, where usually only one measurement per plant is possible.
The canopy height can additionally be used to identify lodge areas. Lodging is defined as the permanent displacement of a plant from the upright position (Berry and Spink, 2012; Rajapaksa et al., 2018) and leads to qualitative and quantitative yield losses of up to $45 \%$ (Berry and Spink, 2012; Peng et al., 2014; Pinthus, 1974; Weibel and Pendleton, 1964). The losses are mainly as a result of the lodging severity and the developmental stage of occurrence (Berry et al., 2004; Fischer and Stapper, 1987; Briggs, 1990). Extreme weather conditions like heavy rain, storm, excessive nitrogen and disease can cause lodging. This results in a growing need to select for genetic lines with greater lodging resistance (Pinthus, 1974). Using UAV data for the spatial assessment of lodging is a very suitable method to automate the detection of lodging and replace laborious and subjective ground data collection. Already Susko et al. (2018) tried to assess crop lodging with a field camera track system. Additionally, Yang et al. (2015) used polarimetric index from RADARSAT-2 data for monitoring wheat lodging. Liu et al. (2018) further used visible and thermal infrared images derived from UAV for rice lodging estimation. Also Murakami et al. (2012) quantified lodging in buckwheat using the 3D canopy structure. In this study, however, the area of lodging was determined by using a threshold at which canopy height lodging occurred, but the application of those thresholds applied in different studies (Bendig, 2015; Chapman et al., 2014; Yang et al., 2017) were defined by subjective inspections rather than by mathematical approaches. The main goal of the presented study is to show a new method using an objective threshold approach that enables the assessment of the lodging percentage without adjusted threshold and subjective decisions.

Additionally, the approach can be used to determine the lodging development, the recovery rate of crops and evaluate the influence of different lodging events based on a multi-temporal consideration of lodging percentage. Navabi et al. (2006) already demonstrated on over 140 different wheat genotypes that the extent of recovery capability varied among genotypes. Similar results were found by Briggs (1990) for barley. 
In general, the lodging percentage parameter is only a decision between presence and absence of lodging. However, the crop canopies can be affected by different lodging severities resulting in different amounts of yield losses. Different studies already investigated the influence of lodging severity related on yield (Berry and Spink, 2012; Fischer and Stapper, 1987; Michael, 1998; Murakami et al., 2012). Ground data based on visual lodging scores are generally insufficient in accuracy, efficiency, and objectivity (Murakami et al., 2012; Simko and Piepho, 2011). Until now, only Chu et al. (2017) tried to assess the lodging severity of corn field by quantifying the number of lodged plants. However, due to the different plant structure and plant density of corn, this approach cannot be applied for cereal crops. Therefore, in this study, a new method is presented that allows to assess the lodging severity of barley using information on how strong the canopy is affected by lodging based on the canopy height variation derived from UAV images.

\section{MATERIALS AND DATA}

\subsection{Study Area}

The study was conducted at Campus Klein-Altendorf agricultural research station of the university of Bonn $\left(50^{\circ} 37^{\prime} \mathrm{N}, 6^{\circ} 59^{\prime} \mathrm{E}\right.$, altitude over sea level $186 \mathrm{~m}$ ), Germany. The study site was an experimental setup consisting of several small breeder plots, each $2.62 \times 3 \mathrm{~m}$ in size. The layout included three different summer barley (Hordeum vulgare) cultivars with two different sowing densities and six repetitions. The codes explained in Table 1 represents the relevant genotypes for the study. The high density (300 seeds $\mathrm{m}^{-2}$ ) reflected the common sowing density in Germany. The lower density consisted of 150 seeds $\mathrm{m}^{-2}$. The selected barley cultivars varied in canopy characteristics and plant height. Sowing was done on 9th April, 2016.

\begin{tabular}{|c|c|}
\hline $\begin{array}{c}\text { Genotype } \\
\text { code }\end{array}$ & Genotype Name \\
\hline 1 & HOR 21770 \\
2 & HOR 9707 \\
3 & HOR 3939 \\
\hline
\end{tabular}

Table 1. Relevant lodge genotypes for study

\subsection{Weather Conditions}

The seasonal development of barley was influenced by environmental conditions recorded at a weather station in situ Campus-Klein-Altendorf. The heavy rain events (Figure 2) especially in June and July influenced the plant development and resulted in a high amount of lodged plants.

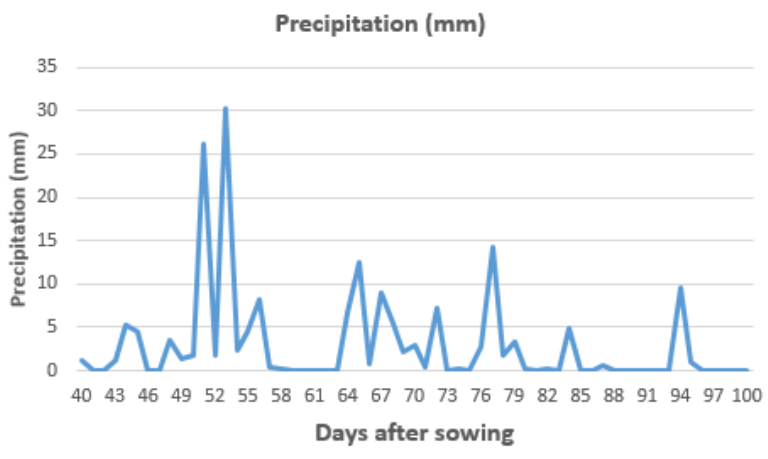

Figure 2. Daily precipitation ( $\mathrm{mm}$ ) between 40 days after sowing to 101 days after sowing

\subsection{UAV Platform and Sensor}

For data acquisition the Falcon-8 UAV (Ascending Technologies $\mathrm{GmbH}$, Krailing, Deutschland) and a Sony (Sony Europe Limited, Weybridge, Surrey, UK) Alpha 6000 RGB camera (24 megapixel, $6000 \times 4000$ pixels) were used. The RGB camera was integrated on a gimbal (Figure 3). Pitch and roll movement of the UAV was balanced and images were acquired according to a planned waypoints pattern with $60 \%$ cross and $80 \%$ forward overlap. Depending on the weather conditions the flight duration varied between 10-15 mins.

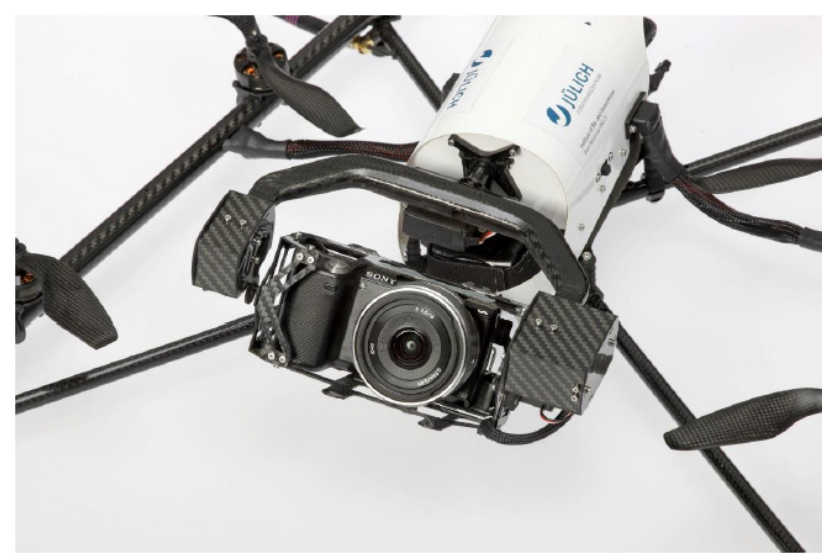

Figure 3. Sony Alpha 6000 camera attached to the Falcon- 8 Octocopter.

\subsection{Data Processing}

Structure from motion (SfM) algorithms were used for processing the UAV images in Agisoft Photoscan (Agisoft LLC, Saint Petersburg, Russia, version 1.4.1). The algorithms identifies corresponding images by feature recognition (Agisoft, 2018). Via a certain number of overlapping images, it recreates their orientation in a spatial three-dimensional (3D) structure (Westoby et al., 2012). Details on the SfM algorithm can be found in several publications (Agisoft, 2018; Kersten, 2016; Lowe, 2004). The primary product of the reconstruction is 3D point cloud, the secondary product is a two-dimensional orthomosaic (Gómez-Candón et al., 2014). Georeferencing (UTM zone $32 \mathrm{~N}$ ) of the point clouds was based on six ground control points (GCPs). For extracting the canopy height model (CHM) the 3D point cloud has to be subtracted from a ground model. The result enables the assessment of canopy height as illustrated in Figure 4.

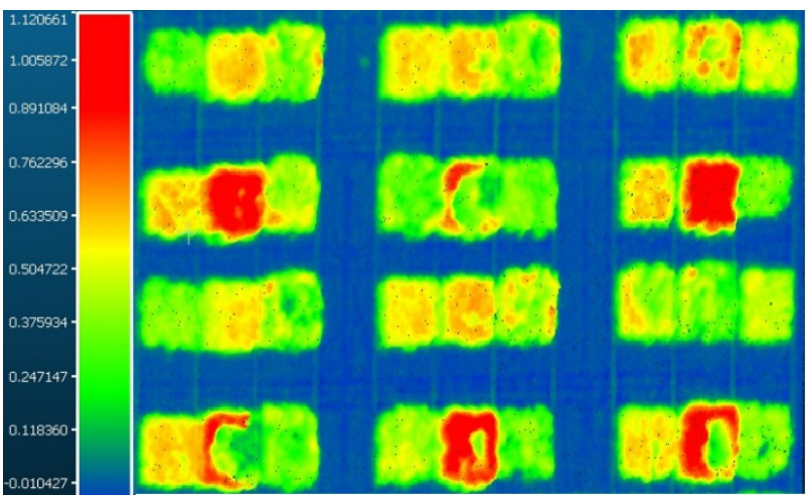

Figure 4. Canopy height (m) within the canopy height model (CHM) with nadir top view

The CHM was rasterized with a spatial resolution of $0.01 \mathrm{~m}$. For further calculation the maximal height value for each grid cell was exported. 


\subsection{Lodging Percentage}

The methodology was focused on a mathematical approach for lodging percentage assessment, avoiding adjusted thresholds and subjective decisions. As a first step, the maximum canopy height (MAXCH) of each genotype were calculated. Related to the $\mathrm{MAXCH}$, three different lodging percentage threshold (LPT) were used to calculate the lodging percentage; $80 \%$ (80LPT), $70 \%$ (70LPT), $60 \%$ (60LPT). Finally, the lodging percentage were determined 75 days after sowing (DAS) by a query (rasterized $\mathrm{CHM}<\mathrm{LPT}$ ) resulting in a binary image with areas influenced or not influenced by lodging.

\subsection{Lodging Development}

The approach additionally enables the determination of recovery rate of crops and evaluates the influence of different lodging events based on a multi-temporal consideration of lodging percentage. The average lodging percentage was calculated for genotypes within experimental setup (Table 1) at five different time points (75 DAS, 81 DAS, 89 DAS, 96 DAS, 102 DAS).

\subsection{Lodging Severity}

For the second lodging parameter four thresholds related to the MAXCH varied from $80 \%$ (80LPT) to $50 \%$ (50LPT) were used to calculate the average lodging severity (ALS) according to Equation (1). Additionally, the weighted average lodging severity (WALS) was calculated (Equal 2). In comparison to ALS the parameter WALS additionally weighted areas of the canopy affected by lodging differentiated regarding the yield impairment. The value range for both formulas varied between 0 and $100 \%$.

$$
\begin{gathered}
A L S=\frac{80 L P T+70 L P T+60 L P T+50 L P T}{4} \\
W A L S=\frac{(0.625 * 80 L P T)+(0.875 * 70 L P T)+(1.125 * 60 L P T)+(1.375 * 50 L P T)}{4}
\end{gathered}
$$

\subsection{Lodging Validation}

The area of lodging were manually determined in additionally acquired high-resolution orthomosaic $(\mathrm{GSD}=2.3 \mathrm{~mm}, 75 \mathrm{DAS})$. Due to the very high resolution, the lodging area were easily identified.

\section{RESULTS AND DISCUSSION}

\subsection{Lodging Percentage}

In order to identify an ideal threshold for UAV lodging percentage assessment, three different LPTs (80LPT, 70LPT, 60LPT) were compared to the reference measurement. The UAV lodging percentage derived from 80LPT let to the lowest correlation $\left(\mathrm{R}^{2}=0.892\right)$ in this comparison (Figure 5a). It became clear that the canopy height deviation between MAXCH and 80LPT were too small for most of the genotypes. Thus, the natural occurring canopy height variation was higher than the predefined threshold and lower grown canopy areas were partly defined as lodge areas resulting in an overestimation of lodging (Figure 5a). The UAV lodging percentage derive from the 70LPT had a high correlation $\left(\mathrm{R}^{2}=0.96\right)$ and the least root-meansquared error (RMSE) (Figure 5b). The 70LPT considered the aforementioned canopy height variation in the field which resulted in high correlation and a low amount of scattering. Comparing the reference measurement with the third UAV lodging percentage derived from the 60LPT, the correlation $\left(\mathrm{R}^{2}\right.$
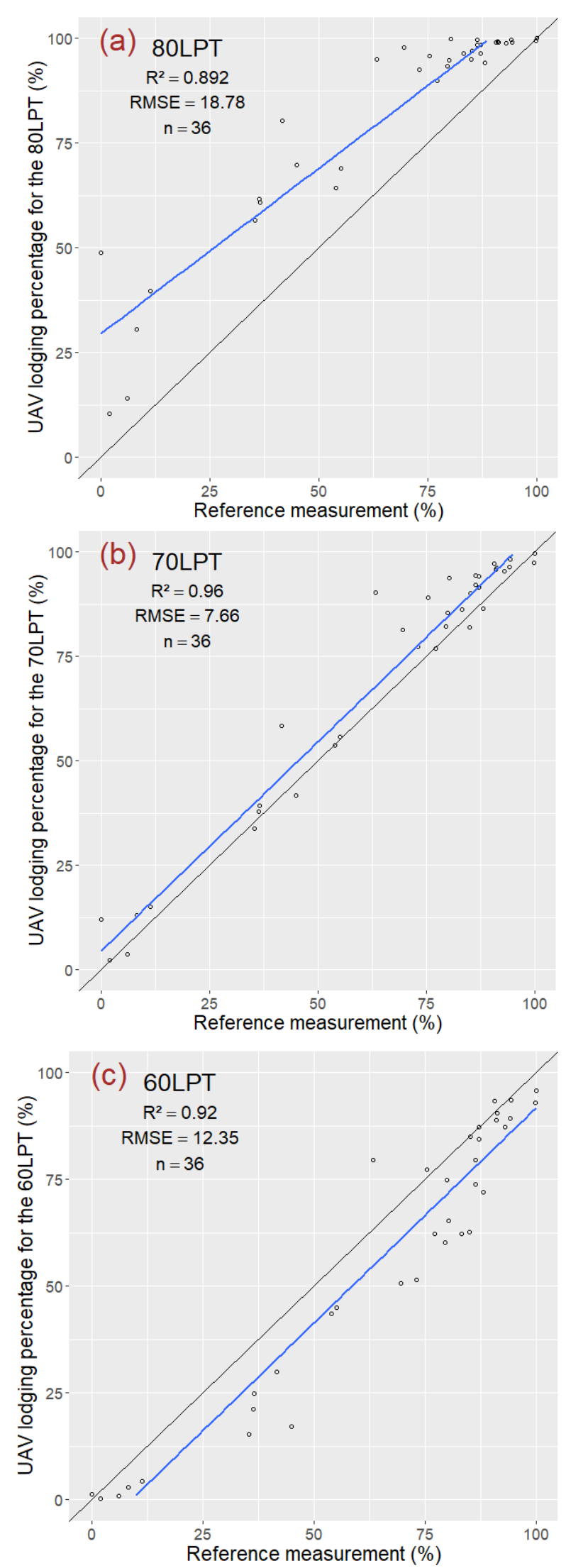

Figure 5. Scatterplots of manually determined lodging percentage (reference measurement) and calculated UAV-based lodging percentage for 80LPT (a), 70LPT (b), 60LPT (c) 75

DAS. Black line represents regression line; blue line represents 1:1 line $(\mathrm{n}=36)$. LPT: lodging percentage threshold; RMSE: root mean square error. 
$=0.921$ ) decreased again (Figure $5 \mathrm{c}$ ). Canopy areas affected by lodging were partly not considered through the lower canopy height threshold. Thus, the lodging percentage was underestimated, especially in the less affected lodging plots, where the canopy height threshold was more relevant.

The UAV lodging percentage parameter was determined with very high accuracy in breeding trials $\left(\mathrm{R}^{2}=0.96\right)$. The results showed, that the 70LPT enabled the detection of lodged areas within the canopy and took into account the $\mathrm{CH}$ variance in the field as well. Liu et al. (2018) and Yang et al. (2017) reached R ${ }^{2}$ greater than 0.9 and a high accuracy by assessing the lodging percentage in rice using structure, texture or thermal difference between presence and absence of lodging. But the accuracy strongly depended on the trained support vector machine (SVM) and the currently dataset. The quantification of lodging from thermal images is also very challenging, because external factors such as small changes in wind speed and cloud cover strongly influence the derived canopy surface temperatures (Chapman et al., 2014; Jackson et al., 1983). The lodging assessment through the UAV canopy height was much more independent from abiotic and external factors. Only a simple RGB camera was necessary without demand for calibration. In general, only large canopy height variations within a field can cause problems. In this extreme case, lower grown plants would be labelled as lodged plants. This issue, however, can be considered in the workflow by applying differentiated $\mathrm{MAXCH}$ values in areas with strong $\mathrm{CH}$ variations caused by different soil or nutrition conditions.

\subsection{Lodging Development}

The approach was additionally used to determine the lodging development like the lodging recovery rate or evaluate the influence of different lodging events based on a multi-temporal consideration of lodging percentage. Considering the multitemporal lodging percentage development for genotype 3 (Figure 6), a low average lodging percentage value of $27 \%$ was observed for plots with low sowing density. That indicated, that most of the plots were not affected by lodging at the beginning of observation (75 DAS). However, caused by a second lodging event, the average lodging percentage increased from $27 \%$ to 60 $\%$ (81 DAS). The plots with high sowing densities showed distinctly larger areas that were heavily affected by lodging. Regarding the lodging development, the average lodging percentage decreased from $80 \%$ to $70 \%$ at the end of observation.

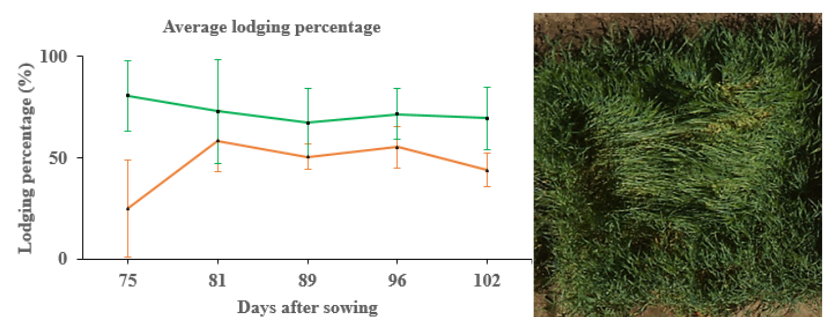

Figure 6. Average lodging percentage (\%) with standard deviation for both sowing densities (high $=$ green, low $=$ orange) and genotype 1 (left). RGB image to illustrate the lodging pattern for genotype 1 (right).

The lodging pattern for genotype 1 was very similar among the plots. The center area was heavily affected by lodging, so that the main part of the plot completely lay on the ground (Figure 6). The outer area were mainly uninfluenced by lodging.

Considering the multi-temporal lodging percentage development of genotype 2, the aforementioned second lodging event could not be observed. Moreover, the lodging percentage for the plots with low sowing densities continuously decreased from $70 \%$ to $55 \%$ (Figure 7). In comparison to the other genotypes, genotype 2 nonetheless had the highest lodging percentage values in both sowing densities. In addition, the standard deviations for plots with high sowing density were very small. In contrast, the lodging percentage for plots with low sowing densities varied between $40 \%$ and $90 \%$.

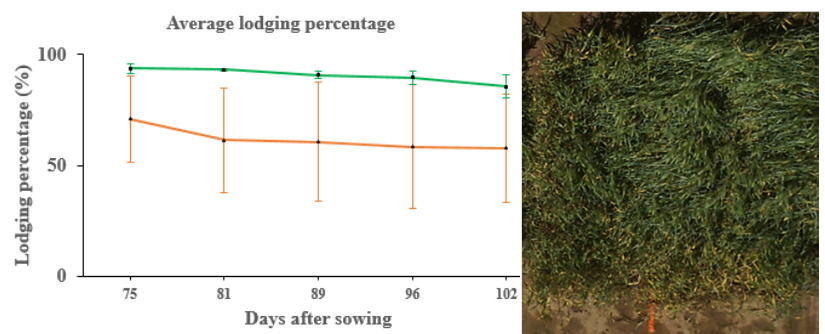

Figure 7. Average lodging percentage (\%) with standard deviation for both sowing densities (high $=$ green, low $=$ orange) and genotype 2 (left). RGB image to illustrate the lodging pattern for genotype 2 (right).

The lodging pattern for genotype 2 was also very homogenous. Although the lodging percentage was in general very high, the lodging severity was low. Mainly, plant apices (spikes) were pressed down, without strong influence on the stems.

The last genotype 3 , had the lowest average lodging percentage compared to other genotypes, but the highest standard deviations. The average lodging percentage was again higher in the low sowing density compared to the high sowing density. The multitemporal observation indicated increasing lodging percentage, although no further lodging event was observed in the field.

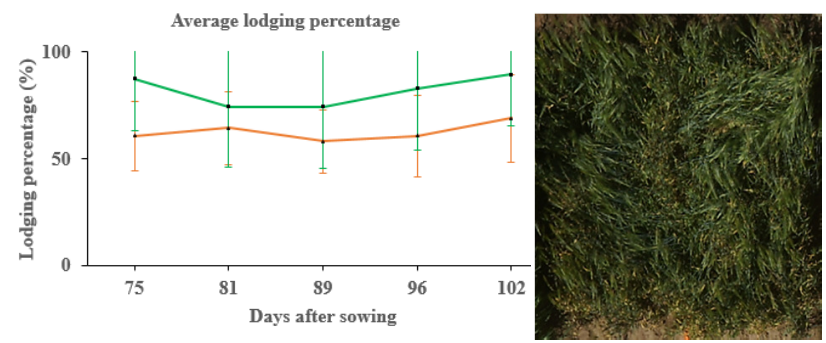

Figure 8. Average lodging percentage (\%) with standard deviation for both sowing densities (high $=$ green, low $=$ orange) and genotype 3 (left). RGB image to illustrate the lodging pattern for genotype 3 (right).

The lodging pattern was quite similar to genotype 2 Only plant apices (spikes) were pressed down, without strong influence on stems.

The results showed that the average lodging percentage of the low sowing density was at least $20 \%$ higher compared to the high sowing density. Already studies from Berry et al. (2002) or Berry et al. (2004) indicated, that lodging risk is reduced with lower sowing densities. This study confirmed additionally, that plants growing in the edges of breeder plots (Figure 6) or plants growing near the wheel tracks were less prone to lodge than plants growing elsewhere in the field. Already the research from Scott et al. (2005) showed that the stronger resistance to lodging was caused by a higher stem strength of edge row plants resulting from reduced competition for resources. Finally, the multitemporal observation illustrated, that different lodging events can be monitored by assessing the lodging percentage at different time points (Figure 6). In contrast, the recovery assessment using multi-temporal lodging percentage calculation was more complicated. The lodging development can be influence by 
plants which sprout out again (Figure 9) due to the high lodging severity and early development stage of occurrence. Consequently, new grown plants (green) decreased the lodging percentage (Figure 6, Genotype 1), but will not mature till harvest and influenced the yield quality negatively.

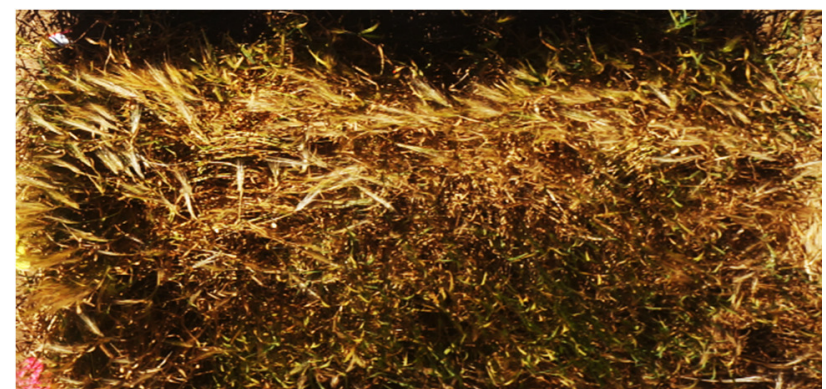

Figure 9. New grown plants (green) after high lodging severity and early development stage of occurrence.

Through the natural seasonal development of cereal crops the canopy height was additionally decreasing from flowering (75 DAS) to ripening (102 DAS). Thus, the absolute height difference between lodge plants and healthy plants was decreasing, resulting in an uncertainty of lodging percentage calculation (Figure 8, Genotype 3). For high accuracy, the lodging percentage should be determined at least two weeks after occurrence.

\subsection{Lodging Severity}

How already illustrated in the previous chapter, plants can be affected by differentiated lodging severities. Respective to the lodging percentage parameter the amount of affected plants below 50LPT were rated equal compared to plants, which were only slightly affected by lodging (area between 80LPT to 60LPT). The lodging severity approach with different thresholds (Figure 10) was able to consider the canopy height variation and the possible yield impairment caused by lodging.
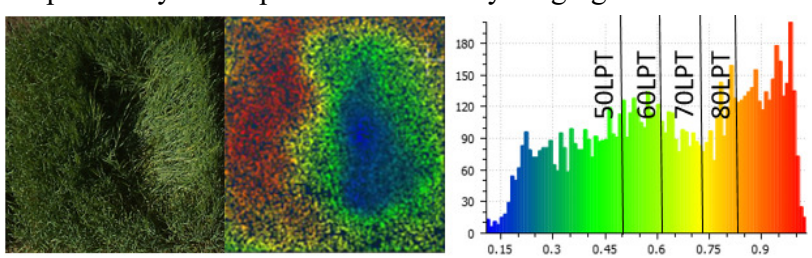

Figure 10. RGB imagery of barley plot showing intensity of lodging (left) and corresponding lodging severity derived from the CHM (middle), as well as canopy height distributions (m) with visualization of different lodging percentage thresholds (LPTs) (right)

The 50LPT applied to the lower density plots allowed detection of only $35 \%$ of lodged area at maximum and $10 \%$ at minimum (Table 2). Contrarily, 70LPT determined a distinctly higher amount of $71 \%$ lodge area at maximum and $27 \%$ at minimum. The applied weighting procedure within the WALS calculation based on the different thresholds was able to consider this lodging intensity variation and, compared to the lodging percentage derived from 70LPT, led to a difference of $16 \%$ at maximum (Table 2). The plots with high sowing density showed distinctly larger areas heavily affected by lodging, with $69 \%$ at maximum and $50 \%$ at minimum for 50LPT. Nevertheless, the variations still present between the different LPTs resulted in a deviation of $15 \%$ at maximum between 70LPT and WALS for the plots with high sowing density. Comparing ALS and WALS clarifies that the weighting procedure applied during WALS calculation consider additionally the yield impairment to a greater extent while ALS probably slightly overestimate the lodging severity. The maximal difference of the WALS values and the ALS values was $6 \%$.

\begin{tabular}{|c|c|c|c|c|c|c|c|c|}
\hline \multirow{2}{*}{ Genotype } & \multirow{2}{*}{$\begin{array}{l}\text { Sowing } \\
\text { density }\end{array}$} & \multicolumn{5}{|c|}{ Lodging percentage (\%) } & \multicolumn{2}{|c|}{$\begin{array}{c}\text { Lodging } \\
\text { severity (\%) }\end{array}$} \\
\hline & & $\begin{array}{c}80 \\
\text { LPT }\end{array}$ & $\begin{array}{c}70 \\
\text { LPT }\end{array}$ & $\begin{array}{c}60 \\
\text { LPT }\end{array}$ & $\begin{array}{c}50 \\
\text { LPT }\end{array}$ & $\begin{array}{c}\text { Reference } \\
\text { measurement }\end{array}$ & WALS & ALS \\
\hline 3 & \multirow{3}{*}{ Low } & 74.70 & 59.94 & 41.74 & 20.76 & 53.97 & 43.66 & 49.29 \\
\hline 2 & & 84.90 & 70.54 & 54.35 & 34.48 & 70.54 & 55.84 & 61.07 \\
\hline 1 & & 44.59 & 26.86 & 16.21 & 9.77 & 24.81 & 20.76 & 24.35 \\
\hline 3 & \multirow{3}{*}{ High } & 94.52 & 86.90 & 73.00 & 50.10 & 77.27 & 71.53 & 76.13 \\
\hline 2 & & 98.10 & 92.86 & 80.94 & 58.44 & 73.28 & 78.49 & 82.58 \\
\hline 1 & & 92.45 & 85.75 & 78.30 & 69.37 & 80.90 & 79.07 & 81.47 \\
\hline
\end{tabular}

Table 2. Overview of UAV lodging percentage for four LPTs $(80 \%, 70 \%, 60 \%, 50 \%)$, ALS and WALS, and manually determined lodging percentage reference data for different sowing densities and genotypes 75 DAS $(n=36)$. LPT: lodging percentage threshold; WALS: weighted average lodging severity; ALS: average lodging severity.

The lodging severity parameter WALS and ALS were able to consider the $\mathrm{CH}$ variance and the information density was compared to a simple binary approach much higher. Several papers (Bendig, 2015; Chapman et al., 2014; Liu et al., 2018; Yang et al., 2017) implemented only a presence or absence of crop lodging and the different lodging severities illustrated in Figure 10 were treated equally. The weighted method implemented to WALS parameter could improve the yield impairment caused by lodging. Already Fischer and Stapper (1987) or Berry and Spink (2012) showed that the yield potential was influenced by the intensity (angle) of the permanent displace from its upright position. Related to the UAV application also Murakami et al. (2012) showed, that the grain yield was impaired stronger by high lodging scores and a low average canopy height. The WALS development was the first step to predict the yield losses of lodge fields. The different factors applied in Equation (2) probably should weighted stronger the lower LTP values but has to be evaluate with yield data comparison in further studies.

\section{CONCLUSION}

Unmanned Aerial Vehicles (UAVs) are increasingly used, and open new opportunities, in agriculture and phenotyping because of the flexible data acquisition. It can provide plant breeders, insurance companies and farmers timely detailed information on plant traits with low monetary costs. Especially breeding trials are difficult and extensive to monitor resulting in an increasing need for a faster selection of superior lines. The lodging quantification based on the 3D canopy structure is compared to other approaches much more independent from environmental conditions, which strongly increases the practicability. Additionally, it enables the possibility to consider the yield impairment caused by lodging. The results showed that the developed method is well suited for barley genotypes and therefore has the potential to be applied to other cereal crops, such as wheat. The pixel-based lodging severity information can be further used in precision farming to generate harvest maps and improve yield quality by avoiding areas in the harvest process that sprout again after heavy lodging events during the early stages of plant development. In summary, the developed lodging assessment approach can be used for insurance applications, precision farming, and breeding research. This trait, together with differentiated recovery are novel traits next to lodging severity will aid the selection for genetic lines. 


\section{ACKNOWLEDGEMENTS}

This study was performed within the German Plant Phenotyping Network (DPPN), which was funded by the German Federal Ministry for Education and Research (BMBF), project identification number BMBF 031A053. The work was additional supported by SPECTORS, which is funded by INTERREG V AProgramm Deutschland-Nederland, project identification number 143081.

\section{REFERENCES}

Aasen, H., Burkart, A., Bolten, A., Bareth, G., 2015. Generating 3D hyperspectral information with lightweight UAV snapshot cameras for vegetation monitoring: From camera calibration to quality assurance. ISPRS J. Photogramm. Remote Sens. https://doi.org/10.1016/j.isprsjprs.2015.08.002

Agisoft, 2018. Agisoft PhotoScan User Manual. Prof. Ed. Version 1.4.

Anthony, D., Elbaum, S., Lorenz, A., Detweiler, C., 2014. On crop height estimation with UAVs, in: IEEE International Conference on Intelligent Robots and Systems. https://doi.org/10.1109/IROS.2014.6943245

Atzberger, C., 2013. Advances in remote sensing of agriculture: Context description, existing operational monitoring systems and major information needs. Remote Sens. 5, 949-981. https://doi.org/10.3390/rs5020949

Bendig, J., Bolten, A., Bareth, G., 2013. UAV-based Imaging for Multi-Temporal, very high Resolution Crop Surface Models to monitor Crop Growth Variability. Photogramm. - Fernerkundung - Geoinf. 6, 551-562. https://doi.org/10.1127/1432$8364 / 2013 / 0200$

Bendig, J., Bolten, A., Bennertz, S., Broscheit, J., Eichfuss, S., Bareth, G., 2014. Estimating biomass of barley using crop surface models (CSMs) derived from UAV-based RGB imaging. Remote Sens. 6, 10395-10412. https://doi.org/10.3390/rs61110395

Bendig, J., Yu, K., Aasen, H., Bolten, A., Bennertz, S., Broscheit, J., Gnyp, M.L., Bareth, G., 2015. Combining UAV-based plant height from crop surface models, visible, and near infrared vegetation indices for biomass monitoring in barley. Int. J. Appl. $\begin{array}{lllll}\text { Earth } & \text { Obs. } & \text { Geoinf. } & \text { 39, } & \text { 79, }\end{array}$ https://doi.org/10.1016/j.jag.2015.02.012

Bendig, J., 2015. Unmanned aerial vehicles ( UAVs ) for multitemporal crop surface modelling. $\mathrm{PhD}$ thesis, Universität $\mathrm{zu}$ Köln.

Berry, P., Spink, J., Sylvester-Bradley, R., Pickett, A., Sterling, M., Baker, C., Cameron, N., 2002. Lodging control through variety choice and management. HGCA Conf. Agron. Intell. Basis Profitab. Prod. 1-12.

Berry, P.M., Spink, J., 2012. Predicting yield losses caused by lodging in wheat. F. Crop. Res. 137, 19-26. https://doi.org/10.1016/j.fcr.2012.07.019

Berry, P.M., Sterling, M., Spink, J.H., Baker, C.J., SylvesterBradley, R., Mooney, S.J., Tams, A.R., Ennos, A.R., 2004. Understanding and Reducing Lodging in Cereals. Adv. Agron. https://doi.org/10.1016/S0065-2113(04)84005-7
Burkart, A., Hecht, V.L., Kraska, T., Rascher, U., 2017. Phenological analysis of unmanned aerial vehicle based time series of barley imagery with high temporal resolution. Precis. Agric. https://doi.org/10.1007/s11119-017-9504-y

Chapman, S., Merz, T., Chan, A., Jackway, P., Hrabar, S., Dreccer, M., Holland, E., Zheng, B., Ling, T., Jimenez-Berni, J., 2014. Pheno-Copter: A Low-Altitude, Autonomous RemoteSensing Robotic Helicopter for High-Throughput Field-Based Phenotyping. Agronomy 4, 279-301. https://doi.org/10.3390/agronomy4020279

Chu, T., Starek, M.J., Brewer, M.J., Murray, S.C., Pruter, L.S., 2017. Assessing lodging severity over an experimental maize (Zea mays L.) field using UAS images. Remote Sens. 9, 1-24. https://doi.org/10.3390/rs9090923

Colomina, I., Molina, P., 2014. Unmanned aerial systems for photogrammetry and remote sensing: A review. ISPRS J. Photogramm. Remote Sens. https://doi.org/10.1016/j.isprsjprs.2014.02.013

Dandois, J.P., Ellis, E.C., 2013. High spatial resolution threedimensional mapping of vegetation spectral dynamics using computer vision. Remote Sens. Environ. https://doi.org/10.1016/j.rse.2013.04.005

De Souza, C.H.W., Lamparelli, R.A.C., Rocha, J.V., Magalhães, P.S.G., 2017. Height estimation of sugarcane using an unmanned aerial system (UAS) based on structure from motion (SfM) point clouds. Int. J. Remote Sens. https://doi.org/10.1080/01431161.2017.1285082

Eling, C., Wieland, M., Hess, C., Klingbeil, L., Kuhlmann, H., 2015. Development and evaluation of a uav based mapping system for remote sensing and surveying applications. Int. Arch. Photogramm. Remote Sens. Spat. Inf. Sci. - ISPRS Arch. 40, 233-239. https://doi.org/10.5194/isprsarchives-XL-1-W4-2332015

Fischer, R.A., Stapper, M., 1987. Lodging effects on highyielding crops of irrigated semidwarf wheat. F. Crop. Res. 17, 245-258. https://doi.org/10.1016/0378-4290(87)90038-4

Briggs, K.G., 1990. Several Six-Row Barley. Cultivars. AGRIS. 181, 173-181. https://doi.org/10.1037/14045-033

Gómez-Candón, D., De Castro, A.I., López-Granados, F., 2014. Assessing the accuracy of mosaics from unmanned aerial vehicle (UAV) imagery for precision agriculture purposes in wheat. Precis. Agric. 15, 44-56. https://doi.org/10.1007/s11119-0139335-4

Grenzdörffer, G., Engel, a, Teichert, B., 2008. The photogrammetric potential of low-cost UAVs in forestry and agriculture. Int. Arch. Photogramm. Remote Sens. Spat. Inf. Sci. 1, 1207-1213. https://doi.org/10.2747/1548-1603.41.4.287

Hodgson, J.C., Baylis, S.M., Mott, R., Herrod, A., Clarke, R.H., 2016. Precision wildlife monitoring using unmanned aerial vehicles. Sci. Rep. https://doi.org/10.1038/srep22574

Holman, F.H., Riche, A.B., Michalski, A., Castle, M., Wooster, M.J., Hawkesford, M.J., 2016. High throughput field phenotyping of wheat plant height and growth rate in field plot trials using UAV based remote sensing. Remote Sens. 8. 
https://doi.org/10.3390/rs8121031

Jackson, R.D., Hatfield, J.L., Reginato, R.J., Idso, S.B., Pinter, P.J., 1983. Estimation of daily evapotranspiration from one timeof-day measurements. Agric. Water Manag. https://doi.org/10.1016/0378-3774(83)90095-1

Kersten, T.P., 2016. Auf Knopfdruck - Auswertung und Resultate UAV-gestützter Bildflugdaten. UAV 2016 Vermessung mit unbemannten Flugsystemen, Schriftenr. des DVW 82, 135-158.

Liu, T., Li, R., Zhong, X., Jiang, M., Jin, X., Zhou, P., Liu, S., Sun, C., Guo, W., 2018. Estimates of rice lodging using indices derived from UAV visible and thermal infrared images. Agric. For. Meteorol. 252, 144-154. https://doi.org/10.1016/j.agrformet.2018.01.021

Lowe, D.G., 2004. Distinctive image features from scaleinvariant keypoints. Int. J. Comput. Vis. 60, 91-110. https://doi.org/10.1023/B:VISI.0000029664.99615.94

Mancini, F., Dubbini, M., Gattelli, M., Stecchi, F., Fabbri, S., Gabbianelli, G., 2013. Using unmanned aerial vehicles (UAV) for high-resolution reconstruction of topography: The structure from motion approach on coastal environments. Remote Sens. https://doi.org/10.3390/rs5126880

Michael, P., 1998. Predicting lodging in winter wheat. PhD thesis, University of Nottingham.

Murakami, T., Yui, M., Amaha, K., 2012. Canopy height measurement by photogrammetric analysis of aerial images: Application to buckwheat (Fagopyrum esculentum Moench) lodging evaluation. Comput. Electron. Agric. 89, 70-75. https://doi.org/10.1016/j.compag.2012.08.003

Navabi, A., Iqbal, M., Strenzke, K., Spaner, D., 2006. The relationship between lodging and plant height in a diverse wheat $\begin{array}{llll}\text { population. Can. J. Plant Sci. 86, 723-726. } & \end{array}$ https://doi.org/10.4141/P05-144

Peng, D., Chen, X., Yin, Y., Lu, K., Yang, W., Tang, Y., Wang, Z., 2014. Lodging resistance of winter wheat (Triticum aestivum L.): Lignin accumulation and its related enzymes activities due to the application of paclobutrazol or gibberellin acid. F. Crop. Res. https://doi.org/10.1016/j.fcr.2013.11.015

Pinthus, M.J., 1974. Lodging in Wheat, Barley, and Oats: The Phenomenon, its Causes, and Preventive Measures. Adv. Agron. https://doi.org/10.1016/S0065-2113(08)60782-8

Rajapaksa, S., Eramian, M., Duddu, H., Wang, M., Shirtliffe, S., Ryu, S., Josuttes, A., Zhang, T., Vail, S., Pozniak, C., Parkin, I., 2018. Classification of Crop Lodging with Gray Level Cooccurrence Matrix. Proc. - 2018 IEEE Winter Conf. Appl. Comput. Vision, WACV 2018 2018-Janua, 251-258. https://doi.org/10.1109/WACV.2018.00034

Scott, D.I., Tams, A.R., Berry, P.M., Mooney, S.J., 2005. The effects of wheel-induced soil compaction on anchorage strength and resistance to root lodging of winter barley (Hordeum vulgare L.). Soil Tillage Res. 82, 147-160. https://doi.org/10.1016/j.still.2004.06.008

Siegmann, B., Jarmer, T., 2015. Comparison of different regression models and validation techniques for the assessment of wheat leaf area index from hyperspectral data. Int. J. Remote Sens. https://doi.org/10.1080/01431161.2015.1084438

Simko, I., Piepho, H.P., 2011. Combining phenotypic data from ordinal rating scales in multiple plant experiments. Trends Plant Sci. https://doi.org/10.1016/j.tplants.2011.02.001

Stanton, C., Starek, M.J., Elliott, N., Brewer, M., Maeda, M.M., $\mathrm{Chu}, \mathrm{T}$., 2017. Unmanned aircraft system-derived crop height and normalized difference vegetation index metrics for sorghum yield and aphid stress assessment. J. Appl. Remote Sens. https://doi.org/10.1117/1.JRS.11.026035

Susko, A.Q., Gilbertson, F., Heuschele, D.J., Smith, K., Marchetto, P., 2018. An automatable, field camera track system for phenotyping crop lodging and crop movement. HardwareX 4. https://doi.org/10.1016/j.ohx.2018.e00029

Turner, D., Lucieer, A., Watson, C., 2012. An automated technique for generating georectified mosaics from ultra-high resolution Unmanned Aerial Vehicle (UAV) imagery, based on Structure from Motion (SFM) point clouds. Remote Sens. https://doi.org/10.3390/rs4051392

Weibel, R.O., Pendleton, J.W., 1964. Effect of Artificial Lodging on Winter Wheat Grain Yield and Quality (AJ). Agron. J. 48, 452-455.

https://doi.org/10.2134/agronj1964.00021962005600050013x

Westoby, M.J., Brasington, J., Glasser, N.F., Hambrey, M.J., Reynolds, J.M., 2012. 'Structure- from- Motion' photogrammetry: A low- cost, effective tool for geoscience applications. Geomorphology 179, 300-314. https://doi.org/10.1016/j.geomorph.2012.08.021

Yang, M. Der, Huang, K.S., Kuo, Y.H., Tsai, H.P., Lin, L.M., 2017. Spatial and spectral hybrid image classification for rice lodging assessment through UAV imagery. Remote Sens. 9. https://doi.org/10.3390/rs9060583

Yang, H., Chen, E., Li, Z., Zhao, C., Yang, G., Pignatti, S., Casa, R., Zhao, L., 2015. Wheat lodging monitoring using polarimetric index from RADARSAT-2 data. Int. J. Appl. Earth Obs. Geoinf. https://doi.org/10.1016/j.jag.2014.08.010

Zhang, C., Kovacs, J.M., 2012. The application of small unmanned aerial systems for precision agriculture: A review. Precis. Agric. 13, 693-712. https://doi.org/10.1007/s11119-0129274-5 